\title{
Primera experiencia y presentación de labores investigadoras referentes a análisis de imágenes médicas para alumnos de enseñanzas medias
}

\author{
Nuria Ortigosa ${ }^{\mathrm{a}, \mathrm{b}}$, Joaquín Cerdá Boluda ${ }^{\mathrm{c}}$ \\ a I.U. Matemática Pura y Aplicada, Universitat Politècnica de València (Spain). \\ nuorar@upvnet.upv.es \\ ${ }^{\mathrm{b}}$ Departament d'Informàtica, Universitat de València (Spain). nuria.ortigosa@uv.es \\ c Instituto de Instrumentación para Imagen Molecular, Universitat Politècnica de València (Spain). \\ joacerbo@upv.es
}

\begin{abstract}
Resumen
Los Campus Científicos de Verano tienen como objetivo que los alumnos de enseñanzas medias de las opciones cientifico-técnicas tengan un primer contacto con la labor investigadora que se realiza en las universidades y centros de investigación. Para ello, los estudiantes participan en proyectos de una semana de duración organizados en diferentes sesiones, como la presentada en este trabajo. Enmarcado en el proyecto "Tecnología y física médicas: la innovación al servicio de la medicina”, cuyo objetivo es fomentar el interés de los alumnos en las aplicaciones tecnológicas de la ingeniería biomédica, presentamos un seminario sobre técnicas de análisis de imágenes biomédicas mediante la utilización del software Mathematica. Realizada en la Universitat Politècnica de València, a los estudiantes se les muestran diferentes técnicas básicas de análisis para, por ejemplo, ser capaces de ubicar el punto de emisión de radiactividad mediante el empleo de histogramas o diferentes técnicas de eliminación de ruido en imágenes procedentes de sistemas para diagnóstico médico. Todo ello se realiza representando los datos de un modo muy visual y adaptando los problemas a resolver a las necesidades del alumnado, motivándolo a través de actividades prácticas tras la presentación de los contenidos teóricos.
\end{abstract}

Palabras clave: ingeniería biomédica, análisis de imagen, habilidades científico-tecnológicas, multidisciplinariedad. 
Primera experiencia y presentación de labores investigadoras referentes a análisis de imágenes médicas para alumnos de enseñanzas medias

\section{Introducción}

En este trabajo se presenta el desarrollo y contenidos realizados en una de las sesiones del Programa Campus Científicos de Verano. Este programa, de una semana de duración, está dirigido a alumnos que han cursado cuarto curso de Educación Secundaria Obligatoria o primer curso de Bachillerato, y tiene el objetivo de que conozcan y experimenten ejemplos de actividad investigadora realizados en diferentes Institutos y Facultades o Escuelas Universitarias.

En particular, este trabajo se centra en las actividades desarrolladas en una de las sesiones del proyecto titulado "Tecnología y Física médicas: la innovación al servicio de la medicina" que tiene lugar en la Universitat Politècnica de València. El objetivo de la sesión es presentar a los alumnos aplicaciones tecnológicas de la ingeniería biomédica e ingeniería electrónica a través del estudio de los registros adquiridos mediante sistemas de imagen para diagnóstico médico mediante el software Wolfram Mathematica.

Para ello, la sesión se inicia presentando las bases de funcionamiento y las ventajas e inconvenientes que presentan diferentes sistemas de imagen utilizados en la práctica clínica, para, a continuación, comenzar a utilizar de forma guiada la herramienta software Mathematica para realizar un procesado básico de ejemplos de algunos de ellos.

\section{Tecnologías de diagnóstico médico mediante imagen}

En la primera parte de la sesión se presentan las tres tecnologías de diagnóstico médico por imagen más utilizadas en la actualidad junto a la ecografía: resonancia magnética nuclear (RMN), tomografía axial computerizada (TAC) y tomografía por emisión de positrones (PET).

\subsection{Resonancia magnética nuclear (RMN)}

En esta prueba diagnóstica se obtienen imágenes del interior del paciente sin utilizar radiaciones ionizantes, mediante la aplicación de un campo magnético constante seguido de un campo magnético variable, de forma que las moléculas de agua que conforman los diferentes tejidos se alinean acorde al campo magnético aplicado. Cuando este campo magnético variable deja de aplicarse, los protones de los diferentes tejidos regresan a su alineamiento inicial, devolviendo la energía que han adquirido.

La resolución de las imágenes obtenidas es alta para tejidos con alto porcentaje de agua en su contenido, como puedan ser músculos, articulaciones y sistemas vascular y nervioso central. 


\subsection{Tomografía Axial Computerizada (TAC)}

La segunda técnica presentada para adquisición de imágenes para diagnóstico médico es la Tomografía Axial Computerizada, basada en la obtención de imágenes mediante la emisión de un haz colimado de rayos $\mathrm{X}$ sobre el paciente. La radiación no absorbida por el mismo es recogida por una serie de deteectores situados alrededor del mismo, cuya información se utiliza para reconstruir una serie de imágenes bidimensionales correspondientes a diferentes "cortes" o secciones del paciente.

El principal inconveniente de esta técnica no invasiva e indolora es la radiación a la que el paciente se ve sometido en la misma, que varía según el área y tejidos sobre los que se realizará la exploración. Sin embargo, la resolución de esta técnica en tejidos duros es muy alta, aportando una calidad de imagen muy superior a la resonancia magnética en este tipo de tejidos.

\subsection{Tomografía por Emisión de Positrones (PET)}

Esta técnica de imagen molecular no invasiva está basada en la inyección de un radiofármaco por vía intravenosa para la obtención de imágenes de forma dinámica, en las que se pueda evaluar la actividad metabólica celular a lo largo del tiempo de la exploración.

Consiste en, una vez inyectado el radiofármaco, detectar y medir la cantidad de fotones gamma emitidos por el paciente que inciden en los detectores dispuestos en forma de anillo alrededor del tomógrafo. La imagen funcional puede obtenerse debido a que en las zonas con mayor demanda de glucosa se detecta una mayor cantidad de fotones gamma. Así, por ejemplo, la imagen de PET tiene aplicaciones principalemente en oncología, debido a que permite estimar puntos de crecimiento celular anormal y el alcance de los mismos, aunque también tiene aplicaciones en neurología y cardiología.

\section{Procesado de registros mediante software Wolfram Mathematica}

La segunda parte de la sesión se inicia presentando el software Wolfram Mathematica, programa ampliamente utilizado en matemáticas, física e ingeniería, cuyo 'kernel' es capaz de realizar cálculos complejos y contar con herramientas de visualización, pero con una una interfaz muy sencilla y amigable, cómoda para interactuar con el usuario del mismo.

Por este motivo fue la herramienta seleccionada para poner en práctica los conceptos que se presentan a continuación. 
Primera experiencia y presentación de labores investigadoras referentes a análisis de imágenes médicas para alumnos de enseñanzas medias

\subsection{Representación de histogramas}

Un histograma es la una representación gráfica de datos agrupados en intervalos, en el que se indica la frecuencia absoluta para los diferentes valores mostrados.

A pesar de que los alumnos ya conocen el concepto de histograma unidimensional por estar incluido en los contenidos de Matemáticas de la educación secundaria, se les recuerda brevemente para, a continuación, presentarles el histograma bidimensional, que será con el que se trabajará en el resto de la sesión.

Dado que no han estudiado todavía el concepto de matriz, la definición de histograma 2D se les introduce de forma intuitiva mediante el ejemplo de un arquero que tira un número determinado de veces una flecha a una diana. Suponiendo que la diana sea rectangular y que sea dividida en diferentes cuadrados, se puede anotar el número de flechas que han caído en cada uno de ellos obteniendo así el histograma correspondiente.

Mediante el ejemplo anterior es intuitivo y directo el paso de la diana rectangular y el arquero al detector de fotones gamma emitidos por el paciente en una prueba mediante PET. En la Figura 1 podemos ver un ejemplo de los presentados en la sesión.
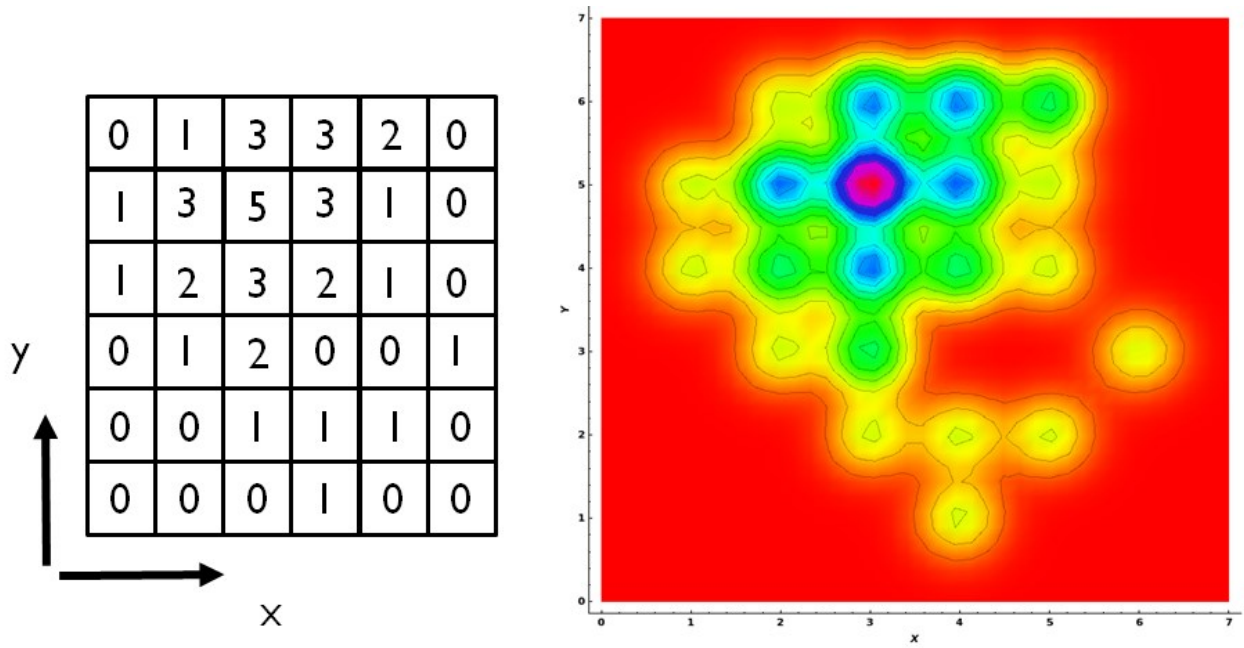

Fig. 1 Ejemplo de histograma 2D con código de colores (derecha) y matriz correspondiente a la izquierda. Fuente: elaboración propia.

Una vez los alumnos han visto algunos ejemplos, comienzan a realizar una práctica guiada con ficheros ASCII que contienen los registros de pruebas PET de pacientes reales, con las posiciones $(\mathrm{x}, \mathrm{y})$ donde inciden los fotones y la energía medida en cada una de ellas, para representar gráficamente el histograma $2 \mathrm{D}$. 


\subsection{Matrices y procesado de imágenes: filtrado}

En esta parte final de la sesión se presentan brevemente algunos conceptos del procesado de imágenes. De este modo, se indica que una imagen digital en blanco y negro no es más que una matriz bidimensional como las que han visto en la sección anterior de la sesión, y se presentan las posibilidades de procesado que ofrece el software Mathematica y su fácil utilización, ya que las mismas vienen ya implementadas para poder hacer uso de ellas directamente.

Así, se presentan las utilidades de la aplicación de umbrales (binarización) sobre los niveles de grises de las imágenes, y operaciones como el filtrado de ruido presente en la imagen y la detección de bordes en la misma. Un ejemplo presentado de la detección de bordes mediante el método de Canny se muestra en la Figura 2.
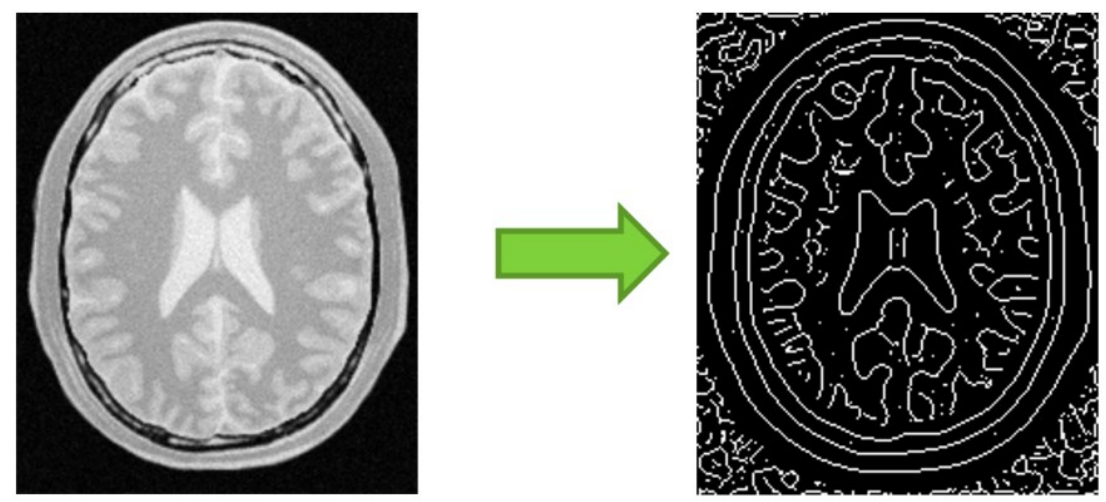

Fig. 2 Detección de bordes en una imagen de TAC de cráneo mediante el método de Canny. Fuente: elaboración propia.

\section{Conclusiones}

En este artículo hemos presentado los conceptos y la estructura del desarrollo de una de las sesiones que se realizan en los Campus Científicos de Verano CAMPUS-VLC para que alumnos de enseñanzas medias tengan un primer contacto con las actividades de investigación en imagen biomédica.

Esta sesión, a lo largo de los diferentes años en los que se ha llevado a cabo, siempre ha obtenido buenos resultados, reflejados por una parte en la motivación que presentan los alumnos y en su comprensión de los conceptos estudiados, así como en la realización de las tareas prácticas asociadas a la misma.

Además, tras finalizar todas las sesiones del Campus Científico, los alumnos preparan una presentación en la que exponen el trabajo que han desarrollado y los conceptos nuevos que 
Primera experiencia y presentación de labores investigadoras referentes a análisis de imágenes médicas para alumnos de enseñanzas medias

han aprendido. Los resultados de la misma siempre han sido satisfactorios, y las encuestas realizadas a los alumnos indican que la experiencia del Campus Científico les ha ayudado en la elección de sus estudios universitarios futuros.

\section{Referencias}

Borrajo-Sánchez J., Cabrero-Fraile F.J. (2010). Tomografía por emisión de positrones (PET): fundamentos y limitaciones tecnológicas. Archivos de la Sociedad Española de Oftamología, 85 no.4, 129-130.

Bushong S.C., Clarke G. (2013). Magnetic Resonance Imaging: Physical and Biological Principles.

Campus Científicos de Verano. Último acceso 5 de octubre de 2018, https://www.campuscientificos.es/

Hofer, M. (2008). Manual práctico de TAC. Ed. Médica Panamericana.

Mangano, S. Mathematica Cookbook (2010). O'Reilly.

VLC/Campus, Campus Científicos de Verano. Último acceso 5 de octubre de 2018, http://www.vlc-campus.com/proyectos/campus-cientificos-de-verano/

Zaragoza, J.R. (1992). Física e instrumentación médica. Ed. Salvat. 